\title{
FUNCTIONAL OUTCOME OF SUBTROCHANTERIC FRACTURES OF FEMUR FIXED WITH DYNAMIC CONDYLAR SCREW (DCS).
}

1. MBBS, MRCS, FCPS Assistant Professor United Medical and Dental College. 2. MBBS, FCPS

Assistant Professor Hamdard University and KVSS Site Hospital Karachi.

3. MBBS, MRCS, FCPS

Consultant Orthopedic Surgeon

4. MBBS, M.Phil

Assistant Professor of Physiology Fatima Memorial College of Dentistry Lahore.

5. MBBS, MRCS, FCPS

Consultant General Surgeon Jinnah post graduate and medical center.

Correspondence Address:

Dr. Masroor Ahmed

United Medical and Dental College. drmasroor68@hotmail.com

Article received on: $15 / 12 / 2018$

Accepted for publication: 25/03/2019

\section{Masroor Ahmed ${ }^{1}$, Ghulam Hussain², Mukesh Kumar ${ }^{3}$, Nida ${ }^{4}$, Rukhsana Hamid ${ }^{5}$}

ABSTRACT... Objectives: To determine functional outcome of Subtrochanteric femur fractures fixed with dynamic condylar screw. Study Design: Single group quasi experimental study. Setting: Orthopedic Surgery, creek general hospital, united medical and dental college and KVSS SITE hospital Karachi. Period: February 2015 to November 2016. Material \& Methods: All the patients with Type $32 A\left(A_{1}, A_{2}\right.$ and $\left.A_{3}\right)$ subtrochanteric fractures of femur presenting within two weeks of injury were included in the study. Functional outcome was assessed by modified Schatzker and Lambert Criteria. Results: 79 patients with closed subtrochanteric fractures were included in study. The mean age of the patients was $41.2 \pm 12.98$ years, mean duration of fracture was $4.58 \pm 1.25$ days. Male to female ratio was 2.04 to $1,42(53.16 \%)$ were injured in road traffic accident and $37(46.84 \%$ ) were due to fall, right side were effected in $40.51 \%$ cases and left side effected in 59.49\% cases. Acceptable functional outcome achieved in $82.28 \%$ (65/79) of cases. Conclusion: We conclude that open reduction and internal fixation are the best procedure to treat difficult fractures like subtrochanteric fractures and to avoid complications like implant failure, nonunion, and mal-union. In our study we attained satisfactory results by the use of dynamic condylar screw in patients with subtrochanteric fracture of femur.

Key words: Dynamic Condylar Screw (DCS), Functional Outcome, Subtrochanteric Femur Fracture (STFF).

Article Citation: Ahmed M, Hussain G, Kumar M, Nida, Hamid R. Functional outcome of Subtrochanteric Fractures femur fixed with Dynamic Condylar Screw (DCS). Professional Med J 2020; 27(2):225-229.

DOI: 10.29309/TPMJ/2020.27.2.2514

\section{INTRODUCTION}

Subtrochanteric fractures report for $10-34 \%$ of hip fractures. ${ }^{1}$ Subtrochanteric region lies between lesser trochanter to about $5 \mathrm{~cm}$ distal to it. STFF have bimodal age of distribution with low energy trauma i.e minor fall and minor trauma are the main reason due to osteoporotic bone in old age people and high energy trauma or fall from a height are the main reasons in young aged people. $^{2}$

Subtrochanteric fractures are difficult to treat because of various anatomic, biologic and biomechanical factors which make this region difficult for treating surgeons. ${ }^{3}$ It is mainly cortical area having poor vascularity, which prolongs the healing time. ${ }^{4}$ there are high tensile and compressive forces in medial cortex distal and lateral to lesser trochanter. Biologically the extensive commination and fragment devitalization compromises bone healing. ${ }^{5}$ Surgical treatment is preferred mode of treatment in case of subtrochanteric fractures in adults. ${ }^{6}$ STFF can be fixed in different ways but no single implant is superior to others in terms of fixation $^{7}$ and includes extramedullary as well as intramedullary devices. In the management of proximal and distal femoral fractures specially $A O$ classification, dynamic condylar screw (DCS) is used to maintaining the blood supply and vitality of all fragments by avoidance of medial dissection. ${ }^{8}$ Present study we find out the outcomes of the DCS in the treatment of subtrochanteric fractures.

\section{MATERIAL \& METHODS}

Single group quasi experimental study was carried out in the department of Orthopedic Surgery, creek general hospital, united medical and dental college and KVSS SITE hospital Karachi from $15^{\text {th }}$ February 2015 to $30^{\text {th }}$ November 
2016. 72 Sample size is based on patient's visits and received surgery during study duration. Nonprobability convenient sampling technique was used. Patients of both sex, aged between 20 to 70 years that presented within 2 weeks of injury were included in study, and patients with pathological fracture, open fracture or associated with any other head or abdominal injury were excluded from study.

After taking informed consent from the patients regarding study and surgery was operated on elective list under spinal anesthesia. Patient in supine position on a traction table, lateral approach was made to the subtrochanteric region. A guide wire was placed on the anterior surface of the femoral neck to determine the anteversion. Another guide pin was inserted across the femoral neck. An appropriate length condylar screw was then applied over the guide. The condylar screw was engaged in the subchondral bone of the lower quadrant of the femoral head. A suitable side plate was applied after attempting anatomic reduction, At least four screws were applied distal to the main fracture. Post-operative rehabilitation was similar in all the patients with active and passive range of motion starting on $1^{\text {st }}$ postoperative day and non-weight bearing mobilization was allowed in $1^{\text {st }}$ week with crutches.

Patients were discharged after 1 week of surgery and then followed up in outpatient department. Final functional outcome was assessed by criteria laid down by Schatzker and Lambert modified by Radford P.J. and Howell C.J, $1992 .^{8}$ (Table-I) at the end of 3rd month of surgery and good to excellent results were recorded as acceptable. All the data were recorded on pre-designed proforma. Data feeding and analysis was done on statistical software packages (SPSS 18.0).

\section{RESULTS}

79 patients with closed subtrochanteric fractures of femur were included in this study. There were $58.2 \%$ cases were below 30 years of age and $41.7 \%$ cases were between 41 to 70 years of age. The mean age of the patients was $41.2 \pm 12.98$ years [Range: 21 - 70] and mean duration of fracture was $4.58 \pm 1.25$ days [Range: $2-10$ as shown in Table-I.

There were 53(67.09\%) male and 26(32.91\%) female patients. Male to female ratio was 2.04 to $1,42(53.16 \%)$ were injured in road traffic accident and $37(46.84 \%)$ were due to fall, similarly right side were effected in $40.51 \%$ cases and left side effected in $59.49 \%$ cases. Out of 53 male, $60.45 \%(32 / 53)$ were injured due to RTA and $39.6 \%(39.6 \%)$ were fall from height while out of 26 female, 38.5\% (10/26) were injured due to RTA and $61.5 \%(16 / 26)$. Surgical procedures on 62 were performed within 5 days while 17 patients were operated in 5 to 10 days.

Functional outcome in our study turned out to be excellent in 29(36.71\%), good in 36 (45.57\%), moderate in $9(11.39 \%)$ and poor in $5(6.33 \%)$. Acceptable functional outcome of subtrochanteric femur fractures fixed by dynamic condylar screw was $82.28 \%$ (65/79) as shown in Figure-1.

Percentile of acceptable outcome was significantly high in below and equal to 40 years of patients having subtrochanteric femur fractures as presented in Table-II, while acceptable outcome was $84.9 \%$ in male and $76.9 \%$ in female as shown in Table-III. Similarly percentage of acceptable outcome was also not significant with respect to mode of delivery and duration of fracture as presented in Table-III.

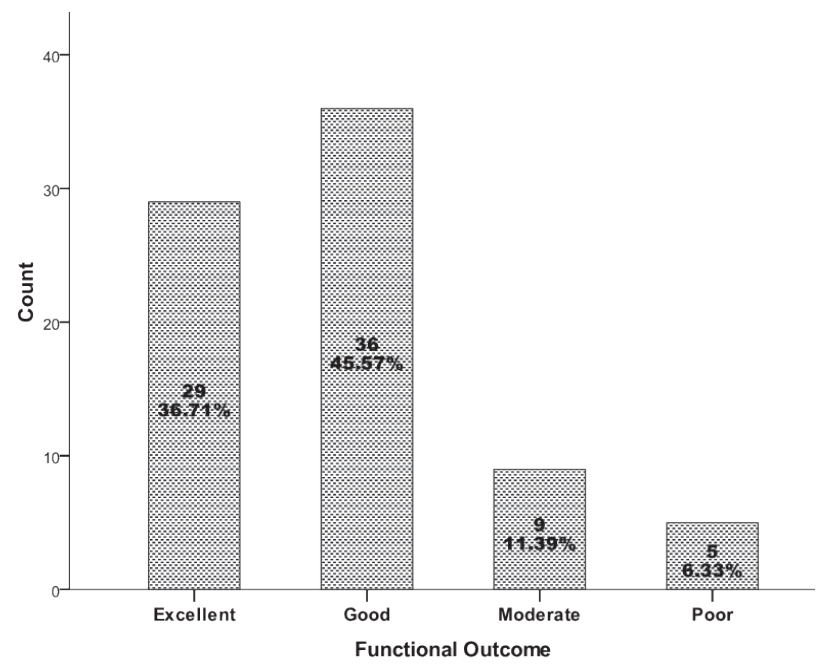

Figure 1. Functional outcome in term of schatzker and lambert criteria $\mathrm{n}=79$ 


\begin{tabular}{|c|c|c|c|}
\hline Excellent & $\begin{array}{l}\text { Good (any one of the } \\
\text { following) }\end{array}$ & $\begin{array}{l}\text { Moderate (any two of the } \\
\text { following) }\end{array}$ & Poor (any of the following) \\
\hline Full extension & Loss of length not $>1.2 \mathrm{~cm}$ & $\begin{array}{l}\text { Loss of length not } \\
>1.2 \mathrm{~cm}\end{array}$ & $\begin{array}{l}\text { Flexion }<90^{\circ} \text { varus or } \\
\quad \text { valgus }>15^{\circ}\end{array}$ \\
\hline Loss of flexion $<10^{\circ}$ & $\begin{array}{l}\text { Varus or valgus deformity } \\
\text { of }<10^{\circ}\end{array}$ & $\begin{array}{c}\text { Varus or valgus deformity } \\
\text { of }<10^{\circ}\end{array}$ & joint incongruence \\
\hline $\begin{array}{l}\text { No varus or valgus } \\
\text { deformity }\end{array}$ & Flexion loss of not $>20^{\circ}$ & Flexion loss of not $>20^{\circ}$ & disabling pain \\
\hline Perfect joint congruency & Minimal pain & Minimal pain & \\
\hline No pain & & & \\
\hline
\end{tabular}

Table-I. Schatzker and lambert criteria modified by radford P.J. and howell C.J. 1992.

\begin{tabular}{|l|l|c|c|}
\hline \multicolumn{2}{|c|}{ Statistics } & Age (Years) & \multicolumn{2}{c|}{ Duration of Fracture (days) } \\
\hline Mean & & 41.20 & 4.58 \\
\hline \multirow{2}{*}{ 95\% Confidence Interval for Mean } & Lower & 38.29 & 4.30 \\
\cline { 2 - 5 } & Upper & 44.11 & 4.86 \\
\hline Median & & 38.00 & 4.00 \\
\hline Std. Deviation & & 12.98 & 1.25 \\
\hline Inter quartile Range & & 16 & 1 \\
\hline
\end{tabular}

Table-I. Descriptive statistics of study patients $n=79$.

\begin{tabular}{|l|c|c|c|}
\hline \multicolumn{1}{|c|}{ Age Groups (Years) } & \multicolumn{2}{|c|}{ Acceptable Outcome } & Total \\
\hline 21 to 30 Years & Yes $(\mathbf{n = 6 5 )}$ & No (n=14) & 18 \\
\hline 31 to 40 Years & $16(88.9 \%)$ & $2(11.1 \%)$ & 28 \\
\hline 41 o 50 Years & $26(92.9 \%)$ & $2(7.1 \%)$ & 16 \\
\hline$>50$ Years & $12(75 \%)$ & $4(25 \%)$ & 17 \\
\hline
\end{tabular}

Chi-Square $=6.87 ; p=0.076$ Linear by Linear Association $=5.27 p=0.022$

Table-II. Functional outcome of subtrochanteric femur fractures fixed by dynamic condylar screw with respect to age groups.

\begin{tabular}{|l|c|c|c|}
\hline \multirow{2}{*}{ Gender } & \multicolumn{2}{|c|}{ Acceptable Outcome } & Total \\
\hline Male & Yes (n=65) & No $(\mathbf{n = 1 4 )}$ & $\mathbf{5 3}$ \\
\hline Female & $45(84.9 \%)$ & $8(15.1 \%)$ & $\mathbf{2 6}$ \\
\hline
\end{tabular}

Chi-Square $=0.76 ; p=0.38$

Table-III. Functional outcome of subtrochanteric femur fractures fixed by dynamic condylar screw with respect to gender.

\section{DISCUSSION}

Treatment of subtrochanteric fractures remains a difficult task, though many implants are available but no single implant is superior to other in terms of fixation of these fractures. Difficulties arise due to biomechanical and anatomical reasons. Main goal in treating these fractures is to achieve anatomical reduction and rigid fixation with adequate union with optimal functional outcome. Dynamic condylar screw provides good fixation in cancellous bone of neck and head along with providing considerable rotational stability. ${ }^{9}$ In our study of 79 patients, the mean age was $41.2 \pm 12.98$ years; Baumagaertal $1994^{11}$ reported a series of 24-subtrochanteric fractures with age range 16-96 years average age 46 years. Regarding Gender status, there were $67.09 \%$ males and $32.91 \%$ female, Buamgaertel $1994^{11}$ reported series of having twenty male (58.7\%) and 10 female patient $(41.3 \%)$ male to female 
ratio was (1.4:1) it is evident that male patients are more commonly affected than females. Road traffic accident was found to be a dominant cause of injury as $53.16 \%$ were injured in road traffic accident and $37(46.84 \%)$ were injured due to fall, Jekic et al $1993^{12}$ reported a series of 63 subtrochanteric fractures 40 patients' sustained fractures due to the road traffic accidents (63.4\%).

There is different outcome of subtrochanteric fractures treated with dynamic condylar screws in different studies done in different countries e.g. study carried out by Radford and Howell in Nottingham showed $64 \%$ excellent to good results, ${ }^{13}$ another study carried out in Kuwait showed $83 \%$ good results using dynamic condylar screw for subtrochanteric fractures ${ }^{14}$ and other study carried out by neogi et al showed 95\% good results. ${ }^{15}$ In our study acceptable practical outcome of subtrochanteric femur fractures fixed by dynamic condylar screw was $82.28 \%(65 / 79)$. DCS fixation for femoral fractures is a very practical and a satisfactory method of fixation. Minimal striping of the soft tissues and gentle fragmentary manipulation intra operatively remained the main factors for fracture healing and functional outcome. ${ }^{16}$ Kulkarni ET al ${ }^{17}$ presented excellent and good results in $77 \%$ of patients and, failure was in $23 \%$ of cases. Sharma in his study that excellent results were obtained in $80 \%$ and good in $12 \%$ and fair in $8 \%$ of patients with subtrochanteric fractures fixed with Dynamic condylar screw. ${ }^{18}$

\section{CONCLUSION}

From our study of 79 patients of subtrochanteric fractures fixed with dynamic condylar screw (DCS), we recommend that the DCS is the excellent implant for management of such fractures because of cost effective ness, availability, functional outcome when comparing with other devices for management of such fractures. We conclude that subtrochanteric fractures are one of the difficult fractures to treat and requires open reduction and internal fixation to avoid complications like non-union, mal-union and implant failure. In our study we achieved sufficient results by the use of dynamic condylar screw in patients with subtrochanteric fracture of femur

\section{CONFLICT OF INTEREST}

Authors hold no conflict of interest in this study. Copyright $@ 25$ Mar, 2019.

\section{REFERENCES}

1. Laghari MA, Makhdoom A, Pahore MK, Memon A, Memon FA. Subtrochanteric femoral fractures treated by fixation with dynamic condylar screw system. JLUMHS. 2011 Sep; 10(03):134.

2. Reiter MJ, Bui-Mansfield LT, O'Brien SD, Tubb CC. Subtrochanteric femur fractures: Review of the complete pathologic spectrum with emphasis on distinguishing imaging features. Journal of computer assisted tomography. 2015 Jan 1; 39(1):47-56.

3. Chaturvedi B, Banerjee S, Ali SI. Study of internal fixation of subtrochantric fracture of femur with dynamic hip screw, dynamic condylar screw and proximal femoral nail. International Journal of Scientific and Research Publications. 2015 Oct.

4. Saini P, Kumar R, Shekhawat V, Joshi N, Bansal M. Biological fixation of comminuted subtrochanteric fractures with proximal femur locking compression plate. Injury. 2013 Feb 28; 44(2):226-31.

5. Krettek C, Müller M, Miclau T. Evolution of minimally invasive plate osteosynthesis (MIPO) in the femur. Injury. 2001 Dec 1; 32:14-23.

6. Stover M. Distal femoral fractures: current treatment, results and problems. Injury. $2001 \mathrm{Dec} 1$; 32:3-13.

7. Canale ST, Lavelle DG, Fracture and dislocation of hip. Campbell's operative orthopedics Philadelphia: Mosby Elsevier; 2003.2897

8. Shroff A, Herode P, Patel JM, Sadaria MH, Nair V. Comparative study between locking compression plate vs. supracondylar nail for supracondylar femur fractures. Orthopedic Research and Reviews. 2016 Oct 9; 1(1).

9. Liu P, Wu X, Shi H, Liu R, Shu H, Gong J, Yang Y, Sun Q, Wu $\mathrm{J}$, Nie X, Cai M. Intramedullary versus extramedullary fixation in the management of subtrochanteric femur fractures: A meta-analysis. Clinical interventions in aging. 2015; 10:803.

10. Gamal M, Amin AH, Kelany O. Comparative study between submuscular biological and open anatomic dynamic condylar screw plating for comminuted subtrochanteric fracture femur in adults. $\mathrm{J}$ Am Sci 2012; 8(11):421-29. 
11. Shah MN, Patel JS. Outcomes of retrograde nailing of distal femoral fractures in Indian population: A prospective study. International Journal of Medical Science and Public Health. 2016 Apr 1; 5(4):769-72.

12. Tang P, Hu F, Shen J, Zhang L, Zhang L. Proximal femoral nail antirotation versus hemiarthroplasty: A study for the treatment of intertrochanteric fractures. Injury. 2012 Jun 30; 43(6):876-81.

13. Ma CH, Tu YK, Yu SW, Yen CY, Yeh JH, Wu CH. Reverse LISS plates for unstable proximal femoral fractures. Injury. 2010 Aug 31; 41(8):827-33.

14. Matre K, Havelin LI, Gjertsen JE, Vinje T, Espehaug $B$, Fevang JM. Sliding hip screw versus IM nail in reverse oblique trochanteric and subtrochanteric fractures. A study of 2716 patients in the Norwegian Hip Fracture Register. Injury. 2013 Jun 30; 44(6):735-42.
15. Neogi DS, Trikha V, Mishra KK, Rohilla N, Yadav CS. Biological plate fixation of comminuted sub trochanteric fractures with the Dynamic Condylar Screw: A clinical study Acta Orthop.Belg.2009, 75, 497503.

16. Haider SA, Asghar A. Dynamic condylar screw fixation for comminuted proximal femur fractures. J Surg Pak.2011 Des; 6(4):11.

17. Kulkarni SS, Moran CJ. Results of dynamic condylar screw for sub trochanteric fractures. Injury. 2003; 34:117-22.

18. Sharma V, Sharma S, Sharma S, Singh N, Dang H: Management of sub trochanteric femoral fractures by dynamic condylar screw (DCS). Internet J Orthop Surg. 2009; 11: 2.

\begin{tabular}{|c|l|l|l|}
\hline \multicolumn{2}{|c|}{ AUTHORSHIP AND CONTRIBUTION DECLARATION } \\
\hline Sr. \# & \multicolumn{1}{|c|}{ Author(s) Full Name } & \multicolumn{1}{|c|}{ Contribution to the paper } & Author(s) Signature \\
\hline 1 & Masroor Ahmed & $\begin{array}{l}\text { Cheif Author, Main concept, } \\
\text { Proof reading. } \\
\text { Review of literature, Proof } \\
\text { reading, Data collection. } \\
\text { References, Review of } \\
\text { literature. } \\
\text { Data analysis. }\end{array}$ \\
\hline 3 & Ghulam Hussain & Mukesh Kumar & $\begin{array}{l}\text { Nida } \\
\text { Data analysis, Reclification of } \\
\text { reviewing. }\end{array}$ \\
\hline 5 & Rukhsana Hamid & Nitum \\
\hline
\end{tabular}

